\title{
ANÁLISE DA ASSOCIAÇÃO ENTRE O PERFIL DE CLIENTE DE UM RESTAURANTE E SEU NÍVEL DE SATISFAÇÃO
}

ANALYSIS OF THE ASSOCIATION BETWEEN THE CUSTOMER'S PROFILE OF A RESTAURANT AND ITS SATISFACTION LEVEL

Fernando de Jesus Moreira Junior ${ }^{1}$, Angela Pellegrin Ansuj', Nicásio Gouveia ${ }^{3}$, José Renê de Oliveira ${ }^{4}$

RECEBIDO: 22/05/2018 | 18/06/2018

DOI: $10.5902 / 2317175832718$

\section{RESUMO}

O objetivo desse trabalho foi analisar a associação entre o perfil de cliente de um restaurante em Santa Maria - RS, segundo sua rotina de refeição e seu nível de satisfação com o restaurante, por meio de análise estatística do teste qui-quadrado e a análise de correspondência. Os clientes foram convidados a responder um questionário para avaliar a satisfação com relação a 28 itens, segundo uma escala likert. Foram encontradas associações significativas com 13 variáveis avaliadas na pesquisa. Os resultados mostraram associações que poderão gerar subsídios para a tomada de decisões e meIhorias no restaurante. Os resultados mais importantes mostraram que existe uma certa deficiência nos serviços prestados durante o almoço do dia de semana com relação ao banheiro, a agilidade dos atendentes, a iniciativa dos atendentes, a preocupação em atender bem o cliente e a disponibilidade dos garçons no atendimento. Também foram encontradas associações com a insatisfação de clientes do buffet de domingo com relação à limpeza, o cheiro do ambiente interno e o estacionamento.

Palavras-chave: Pesquisa de satisfação; Clientes; Restaurantes; Teste qui-quadrado, Análise de Correspondência.

1 Docente do Departamento de Estatística / CCNE / UFSM. Formação: Graduação em Estatística (UFRGS), Mestrado em Engenharia de Produção (UFRGS), Doutorado em Engenharia de Produção (UFSC).

2 Professora Titular do Departamento de Estatística / CCNE / UFSM. Formação: Graduação em Ciências Contábeis (UFSM), Mestrado em Engenharia de Produção (UFSM), Doutorado em Engenharia de Produção (UFSM).

3 Formação: Bacharel em Estatística (UFSM). Acadêmico do Curso de Especialização em Estatística e Modelagem Quantitativa.

4 Formação: Bacharel em Administração. Mestre em Engenharia de Produção (UFSM).Acadêmico do Curso de Bacharelado em Geografia. 


\begin{abstract}
The aim of this study was to analyze the association between the customer's profile of a restaurant in Santa Maria - RS, according to their meal routine and their level of satisfaction with the restaurant, through statistical analysis of chi-square test and correlation analysis. Customers were asked to answer a questionnaire to assess satisfaction with respect to 28 items, according to a Likert scale. Significant associations were found with 13 variables measured in the survey. The results showed associations that may generate subsidies for decision-making and improvements in the restaurant. The most important results showed that there is some deficiency in the services provided during the weekday lunch with regard to the bathroom, the agility of the attendants, the initiative of the attendants, the concern to meet the customer well and availability of waiters in attendance. They also found associations with dissatisfaction Sunday buffet customers regarding the cleaning, the smell of indoor and parking.
\end{abstract}

Keywords: Satisfaction Survey; Customers; restaurants; Chi-square test; Correspondence Analysis

\title{
1 Introdução e Objetivos
}

As inúmeras atividades absorvidas pelas pessoas, tais como estudo, trabalho, criação dos filhos, atividades religiosas, esportivas e sociais, entre outras, têm reduzido drasticamente seu tempo livre. Tudo isso contribuiu para que elas mudassem seus hábitos alimentares, de maneira que muitas delas começaram a realizar as refeições fora de casa, em restaurantes comerciais, aumentando consideravelmente esse mercado e a concorrência (OLIVEIRA et al., 2015). Segundo Passador et al. (2006), a busca pela praticidade, somada à falta de tempo e, ainda, a distância entre o local de trabalho e a residência, fez com que as pessoas mudassem seus hábitos alimentares, de maneira que muitas começaram a realizar as refeições fora de casa. Dessa forma, as empresas devem se preocupar em oferecer serviços que satisfaçam as necessidades dos clientes e suas expectativas.

Segundo Pinheiro et al. (2008), o setor de serviços possui características peculiares que o diferem do industrial, pois muitas vezes, uma organização é resultado da fusão de uma empresa prestadora de serviço com outra de bens, como é o caso das empresas do setor de alimentação, que fornecem a refeição, servida no restaurante, como um produto tangível e a prestação de serviços como um serviço intangível que são as sensações percebidas pelos clientes. Conforme Tontini e Sant'ana (2007), a satisfação do cliente está relacionada com o atendimento do consumidor, através do conjunto de características ou atributos do serviço ou produto. Dessa forma, torna-se importante identificar como o desempenho dos diferentes atributos está relacionado à satisfação dos clientes.

O objetivo desse trabalho é analisar a associação entre o perfil de cliente de um restaurante em Santa Maria - RS, segundo seus hábitos de refeição e seu nível de satisfação com o restaurante, por meio de análise estatística do teste qui-quadrado e a análise de correspondência. 


\section{Revisão da Literatura}

De acordo com Kotler (1994), satisfação é o nível de sentimento de uma pessoa resultante da comparação do desempenho ou resultado de um produto (ou serviço) em relação a suas expectativas.

Segundo Oliver (1993), clientes constroem suas expectativas de préconsumo, examinam o produto/serviço, relacionam suas expectativas e tiram conclusões baseadas no conhecimento adquirido, formando desse modo, sua avaliação de satisfação.Além disso, Bortolotti et al. (2012) destaca que a satisfação de um consumidor é uma questão de sobrevivência para qualquer organização e que a busca contínua da satisfação dos clientes é um dos objetivos mais importantes de um atendimento de boa qualidade.

Em restaurantes, a satisfação é estudada observando os serviços prestados, ela resulta de um conjunto de atributos, qualidade da comida, a variedade do cardápio oferecido, ambiente físico, e período de espera. (DUBE, 1994). Para o cliente é importante ter um local agradável para que se sinta bem, e os serviços prestados, incluindo alimentos com qualidade, o façam retornar (BARLOW; MOLLER, 1996).Os dados sobre os níveis de satisfação dos clientes formam uma das maiores prioridades na administração nas empresas que se comprometem com a qualidade dos seus serviços e produtos, por meio das informações obtidas junto aos seus clientes ou consumidores. Quanto maior o grau de satisfação, maior a lucratividade de uma empresa, muitas vezes chega a ser acima da média. (ROSSI; SLONGO, 1998). Isso faz com que os recursos destinados a aumentar a satisfação do consumidor sejam considerados como investimentos e não como despesas (BORTOLOTTI et al., 2012).

\section{Metodologia}

Os dados foram levantados no período de agosto 2013 a agosto de 2014, por meio da aplicação de um questionário que avaliou o nível de satisfação dos clientes do restaurante e a importância que os mesmos atribuíram a 28 aspectos do restaurante. Os clientes foram convidados a avaliar, para cada item, a sua satisfação e a sua atribuição de importância, ambas numa escala likert de cinco pontos. Esse trabalho delimita-se a apresentar apenas os resultados relacionados com satisfação do cliente que tiveram associação significativa com a variável "refeição" a qual verificava qual o tipo de refeição que o cliente estava fazendo ou fez no estabelecimento, se era almoço de dia de semana, jantar de dia de semana ou buffet de domingo. Para verificar estatisticamente a associação entre as variáveis, foi utilizado o teste quiquadrado. Para verificar graficamente a associação entre as variáveis, foi utilizada a análise de correspondência (AC). Para fins de análises, as respostas originais foram agrupadas em três categorias: insatisfeito (1), que abrangeu as categorias muito insatisfeito (1)e insatisfeito(2); razoável (2) que abrangeu a 
categoria razoável (3); e satisfeito (3), que abrangeu as categorias satisfeito (4) e muito satisfeito(5).

Para o teste qui-quadrado, as tabelas cruzadas e a análise de correspondência (AC) foi utilizado o software SPSS. Essa pesquisa faz parte de um projeto acadêmico que foi devidamente avaliado e aprovado pelo Comitê de Ética em Pesquisa da Universidade Federal de Santa Maria (UFSM), tendo sido registrado no Gabinete de Projetos (GAP) do Centro de Ciências Naturais e Exatas (CCNE), sob o número 032844.

\section{Resultados e Discussão}

A variável "refeição", que definia o perfil do cliente, segundo seus hábitos de refeição, verificava qual o tipo de refeição que o cliente estava fazendo ou fez no estabelecimento. Existiam três possibilidades: (1) almoço de dia de semana, (2) jantar de dia de semana ou (3) buffet de domingo. Foram encontradas associações significativas com 13 variáveis avaliadas na pesquisa. Os resultados e a discussão são apresentados a seguir. Nas tabelas apresentadas abaixo, as casas marcadas com asterisco (*) indicam a associação significativa encontrada entre as categorias das variáveis.

Foi encontrada associação significativa $(p=0,038)$ com a variável "banheiro". A Tabela 1 apresenta o percentual de clientes segundo o tipo de refeição e a satisfação com o banheiro do estabelecimento. O gráfico da AC é apresentado na Figura 1. Conclui-se que os clientes que almoçam durante a semana têm maior tendência de estarem insatisfeitos com o banheiro, aqueles que jantam durante a semana têm maior tendência de estarem satisfeitos com o banheiro, enquanto que aqueles que frequentam o buffet de domingo têm maior tendência de achar que o banheiro está razoável.

Tabela 1: Tipo de refeição X satisfação com o banheiro.

\begin{tabular}{|c|c|c|c|c|}
\hline \multicolumn{5}{|c|}{ Banheiro } \\
\hline Refeição & Insatisfeito & Razoável & Satisfeito & TOTAL \\
\hline Almoço de dia de semana (À la carte) & $9,0 \%$ * & $30,5 \%$ & $60,6 \%$ & $100,0 \%$ \\
\hline Jantar de dia de semana (À la carte) & $3,9 \%$ & $28,3 \%$ & $67,8 \%$ * & $100,0 \%$ \\
\hline Buffet de domingo & $6,7 \%$ & $39,5 \%$ * & $53,8 \%$ & $100,0 \%$ \\
\hline TOTAL & $6,8 \%$ & $31,5 \%$ & $61,7 \%$ & $100,0 \%$ \\
\hline
\end{tabular}

Fonte: elaboração própria. 
ANÁLISE DA ASSOCIAÇÃO ENTRE O PERFIL DE CLIENTE DE UM RESTAURANTE E SEU NÍVEL DE SATISFAÇÃO

Figura 1 - 0 gráfico da AC entre Tipo de refeição e satisfação com o banheiro

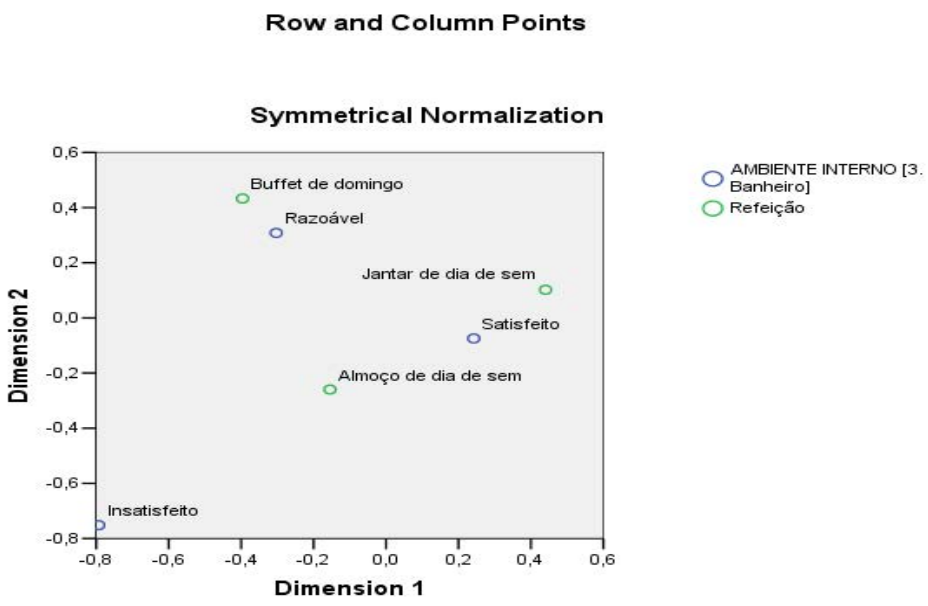

Fonte: elaboração própria.

A variável "refeição" também teve associação significativa $(p=0,003)$ com a variável "limpeza". A Tabela 2 apresenta o percentual de clientes segundo o tipo de refeição e a satisfação com a limpeza do estabelecimento. O gráfico da AC é apresentado na Figura 2.

Tabela 2: Tipo de refeição X satisfação com a limpeza.

\begin{tabular}{|c|c|c|c|c|}
\hline & Limpeza & & & \\
\hline Refeição & Insatisfeito & Razoável & Satisfeito & TOTAL \\
\hline Almoço de dia de semana (À la carte) & $6,3 \%$ & $20,7 \%$ & $73,0 \%$ & $100,0 \%$ \\
\hline Jantar de dia de semana (À la carte) & $6,9 \%$ & $15,7 \%$ & $77,3 \% *$ & $100,0 \%$ \\
\hline Buffet de domingo & $16,9 \%$ * & $20,2 \%$ & $62,9 \%$ & $100,0 \%$ \\
\hline TOTAL & $8,7 \%$ & $18,9 \%$ & $72,5 \%$ & $100,0 \%$ \\
\hline
\end{tabular}


Figura 2 - 0 gráfico da AC entre Tipo de refeição e satisfação com a limpeza

Row and Column Points

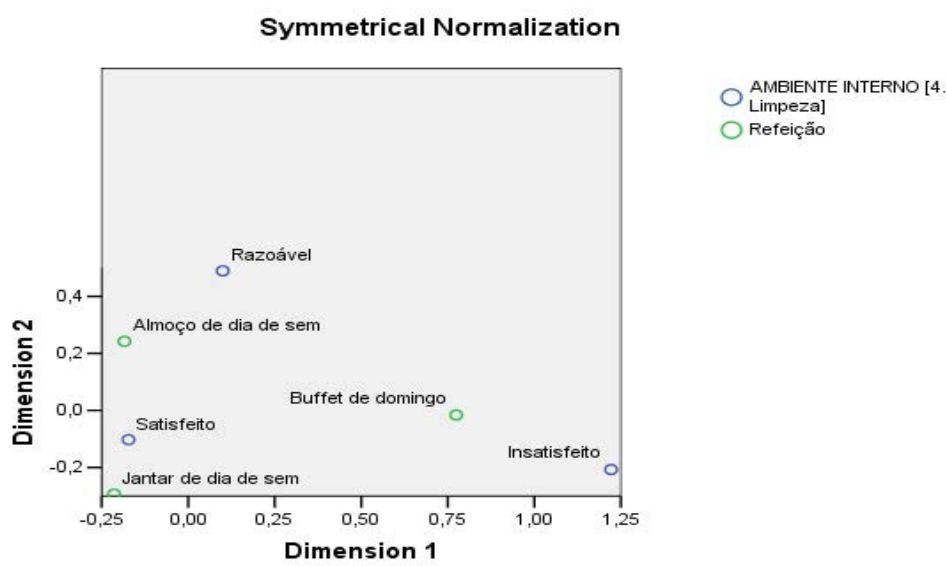

Fonte: elaboração própria.

Conclui-se que os clientes que frequentam o buffet de domingo têm maior tendência de estarem insatisfeitos com a limpeza, enquanto que aqueles que jantam durante a semana têm maior tendência de estarem satisfeitos com a limpeza.

A variável "refeição" também teve associação significativa $(p=0,004)$ com a variável "cheiro". A Tabela 3 apresenta o percentual de clientes segundo o tipo de refeição e a satisfação com o cheiro do estabelecimento. $O$ gráfico da AC é apresentado na Figura 3. Conclui-se que os clientes que frequentam o buffet de domingo têm maior tendência de estarem insatisfeitos com o cheiro, enquanto que aqueles que jantam durante a semana têm maior tendência achar que o cheiro está razoável.

Tabela 3: Tipo de refeição X satisfação com o cheiro.

\begin{tabular}{|c|c|c|c|c|}
\hline \multicolumn{5}{|c|}{ Cheiro } \\
\hline Refeição & Insatisfeito & Razoável & Satisfeito & TOTAL \\
\hline Almoço de dia de semana (À la carte) & $23,0 \%$ & $10,8 \%$ & $66,2 \%$ & $100,0 \%$ \\
\hline Jantar de dia de semana (À la carte) & $18,2 \%$ & $17,3 \%$ * & $64,5 \%$ & $100,0 \%$ \\
\hline Buffet de domingo & $34,7 \%$ * & $10,5 \%$ & $54,8 \%$ & $100,0 \%$ \\
\hline TOTAL & $23,7 \%$ & $13,0 \%$ & $63,3 \%$ & $100,0 \%$ \\
\hline
\end{tabular}

Fonte: elaboração própria. 
ANÁLISE DA ASSOCIAÇÃO ENTRE O PERFIL DE CLIENTE DE UM RESTAURANTE E SEU NÍVEL DE SATISFAÇÃO

Figura 3 - 0 gráfico da AC entre Tipo de refeição e satisfação com o cheiro

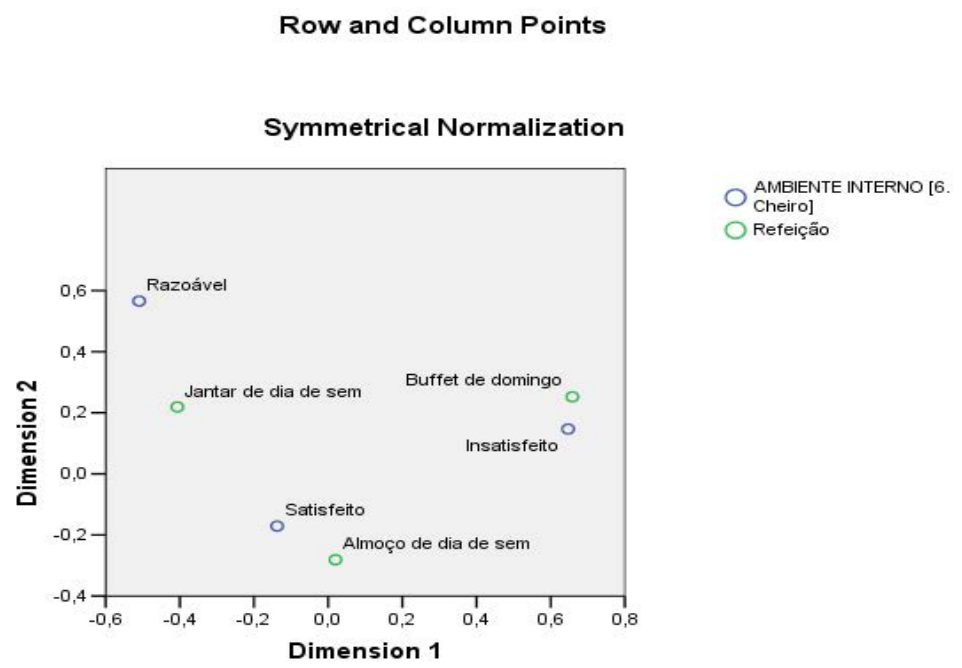

Fonte: elaboração própria.

A variável "refeição" também teve associação significativa $(p=0,019)$ com a variável "sinalização externa". A Tabela 4 apresenta o percentual de clientes segundo o tipo de refeição e a satisfação com a sinalização do estabelecimento. O gráfico da AC é apresentado na Figura 4. Conclui-se que aqueles que almoçam durante a semana têm maior tendência de estarem satisfeitos com a sinalização, enquanto que aqueles que jantam durante a semana têm maior tendência achar que a sinalização é razoável.

Tabela 4: Tipo de refeição X satisfação com a sinalização.

\begin{tabular}{lllll}
\hline \multicolumn{5}{c}{ Sinalização } \\
\hline Refeição & Insatisfeito & Razoável & Satisfeito & TOTAL \\
\hline Almoço de dia de semana (À la carte) & $4,8 \%$ & $15,9 \%$ & $79,3 \%^{*}$ & $100,0 \%$ \\
Jantar de dia de semana (À la carte) & $6,2 \%$ & $28,1 \%{ }^{*}$ & $65,7 \%$ & $100,0 \%$ \\
Buffet de domingo & $5,6 \%$ & $21,0 \%$ & $73,4 \%$ & $100,0 \%$ \\
TOTAL & $5,5 \%$ & $21,2 \%$ & $73,4 \%$ & $100,0 \%$ \\
\hline FoTe
\end{tabular}

Fonte: elaboração própria. 
Figura 4 - 0 gráfico da AC entre Tipo de refeição e satisfação com a sinalização

Row and Column Points

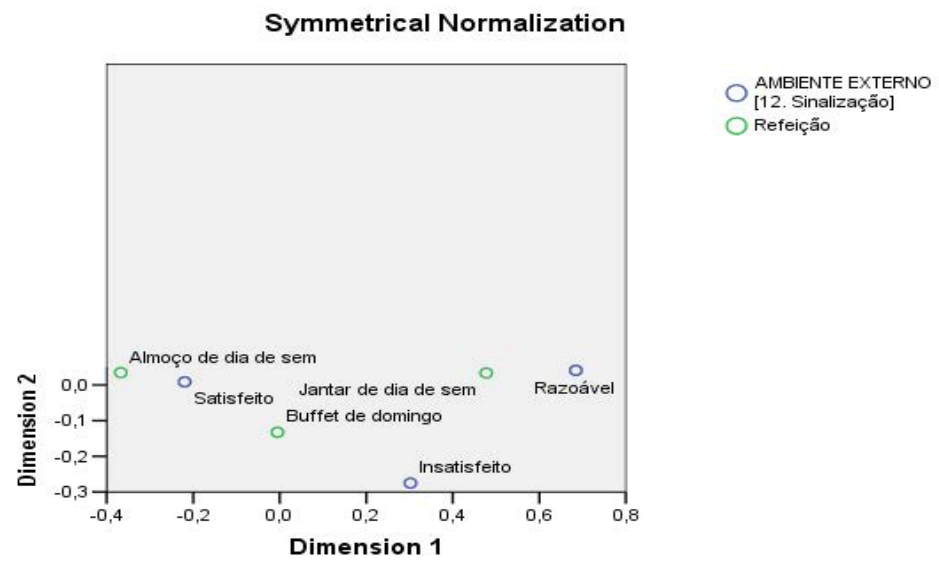

Fonte: elaboração própria

A variável "refeição" também teve associação significativa $(p=0,001)$ com a variável "estacionamento". A Tabela 5 apresenta o percentual de clientes segundo o tipo de refeição e a satisfação com a limpeza do estabelecimento. O gráfico da AC é apresentado na Figura 5. Conclui-se que os clientes que frequentam o buffet de domingo têm maior tendência de estarem insatisfeitos com o estacionamento, enquanto que aqueles que almoçam durante a semana têm maior tendência de estarem satisfeitos com o estacionamento.

Tabela 5: Tipo de refeição X satisfação com o estacionamento.

\begin{tabular}{lllll}
\hline \multicolumn{5}{l}{ Estacionamento } \\
\hline Refeição & Insatisfeito & Razoável & Satisfeito & TOTAL \\
\hline Almoço de dia de semana (À la carte) & $15,4 \%$ & $23,9 \%$ & $60,7 \%{ }^{*}$ & $100,0 \%$ \\
Jantar de dia de semana (À la carte) & $15,2 \%$ & $27,2 \%$ & $57,6 \%$ & $100,0 \%$ \\
Buffet de domingo & $29,6 \%{ }^{*}$ & $30,4 \%$ & $40,0 \%$ & $100,0 \%$ \\
TOTAL & $18,2 \%$ & $26,4 \%$ & $55,5 \%$ & $100,0 \%$ \\
\hline Fonte: elaboração própria. & & & &
\end{tabular}

Fonte: elaboração própria. 
ANÁLISE DA ASSOCIAÇÃO ENTRE O PERFIL DE CLIENTE DE UM RESTAURANTE E SEU NÍVEL DE SATISFAÇÃO

Figura 5 - 0 gráfico da AC entre Tipo de refeição e satisfação com o estacionamento

Row and Column Points

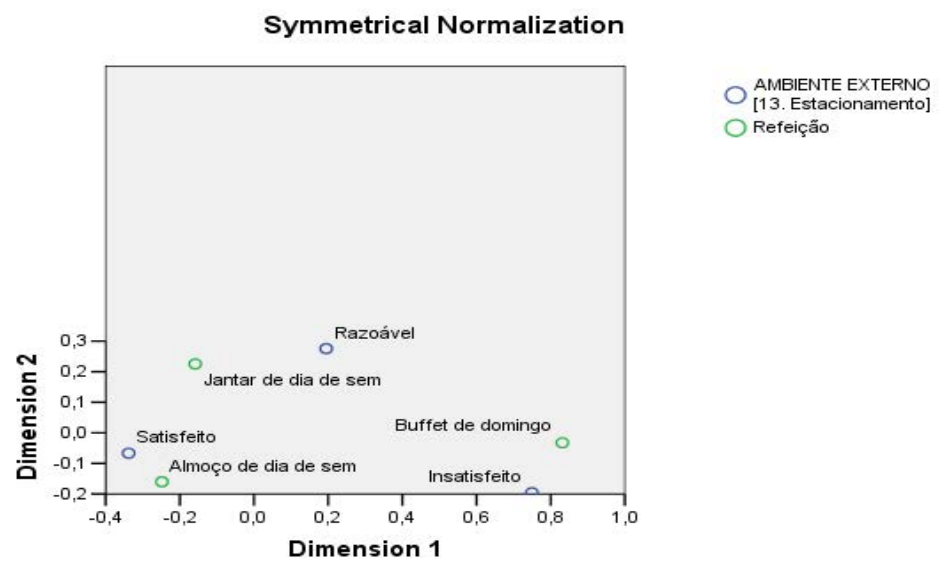

Fonte: elaboração própria.

A variável "refeição" também teve associação significativa $(p<0,001)$ com a variável "organização do buffet". A Tabela 6 apresenta o percentual de clientes segundo o tipo de refeição e a satisfação com a organização do buffet do estabelecimento. $O$ gráfico da AC é apresentado na Figura 6.

Tabela 6: Tipo de refeição $X$ satisfação com organização do buffet.

\begin{tabular}{lllll}
\hline \multicolumn{4}{l}{ Organização do buffet } \\
\hline Refeição & Insatisfeito & Razoável & Satisfeito & TOTAL \\
\hline Almoço de dia de semana (À la carte) & $3,9 \%$ & $39,8 \% \%^{*}$ & $56,4 \%$ & $100,0 \%$ \\
Jantar de dia de semana (À la carte) & $4,8 \%$ & $37,9 \%$ & $57,3 \%$ & $100,0 \%$ \\
Buffet de domingo & $0,0 \%$ & $15,6 \%$ & $84,4 \% \%^{*}$ & $100,0 \%$ \\
TOTAL & $3,4 \%$ & $34,3 \%$ & $62,3 \%$ & $100,0 \%$ \\
\hline Fonte: elaboração própria. & & & &
\end{tabular}




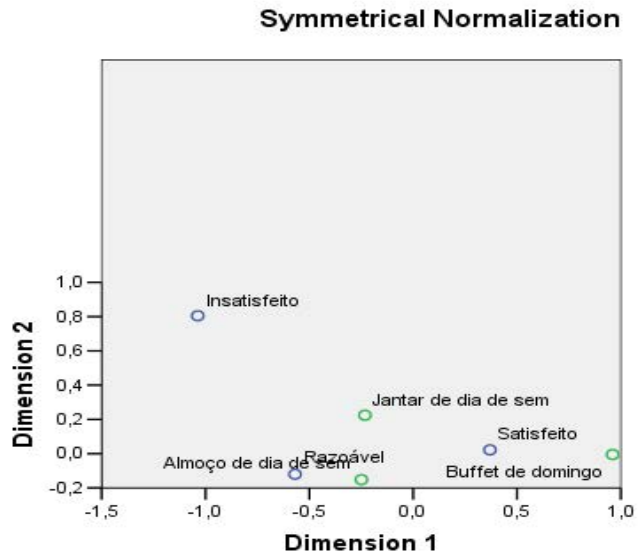

ALIMENTACCÃO [14. Organizaçẩo do Buffet
(distribuiçẫo dos (distribuiç prastos

Fonte: elaboração própria.

Conclui-se que os clientes que frequentam o buffet de domingo têm maior tendência de estarem satisfeitos com a organização do buffet, enquanto que aqueles que almoçam durante a semana têm maior tendência de achar que o buffer está razoavelmente organizado.

A variável "refeição" também teve associação significativa $(p=0,008)$ com a variável "apresentação e identificação dos pratos". A Tabela 7 apresenta o percentual de clientes segundo o tipo de refeição e a satisfação com a apresentação e identificação dos pratos do estabelecimento. O gráfico da $A C$ é apresentado na Figura 7. Conclui-se que aqueles que almoçam durante a semana têm maior tendência de estarem satisfeitos com a apresentação e identificação dos pratos, enquanto que os clientes que frequentam o buffet de domingo têm maior tendência de achar que os pratos estão razoavelmente apresentados e identificados.

Tabela 7: Tipo de refeição X satisfação com apresentação e identificação dos pratos.

\begin{tabular}{lllll}
\hline & \multicolumn{4}{l}{$\begin{array}{l}\text { Apresentação e identificação dos } \\
\text { pratos }\end{array}$} \\
\hline Refeição & Insatisfeito & Razoável & Satisfeito & TOTAL \\
\hline Almoço de dia de semana (À la carte) & $3,0 \%$ & $15,0 \%$ & $82,0 \%^{*}$ & $100,0 \%$ \\
Jantar de dia de semana (À la carte) & $4,9 \%$ & $18,5 \%$ & $76,6 \%$ & $100,0 \%$ \\
Buffet de domingo & $3,3 \%$ & $30,1 \%{ }^{*}$ & $66,7 \%$ & $100,0 \%$ \\
TOTAL & $3,7 \%$ & $19,3 \%$ & $77,0 \%$ & $100,0 \%$ \\
\hline Fonte: elaboração própria. & & & &
\end{tabular}


ANÁLISE DA ASSOCIAÇÃO ENTRE O PERFIL DE CLIENTE DE UM RESTAURANTE E SEU NÍVEL DE SATISFAÇÃO

Figura 7 - 0 gráfico da AC entre Tipo de refeição e satisfação com a apresentação e identificação dos pratos

Row and Column Points

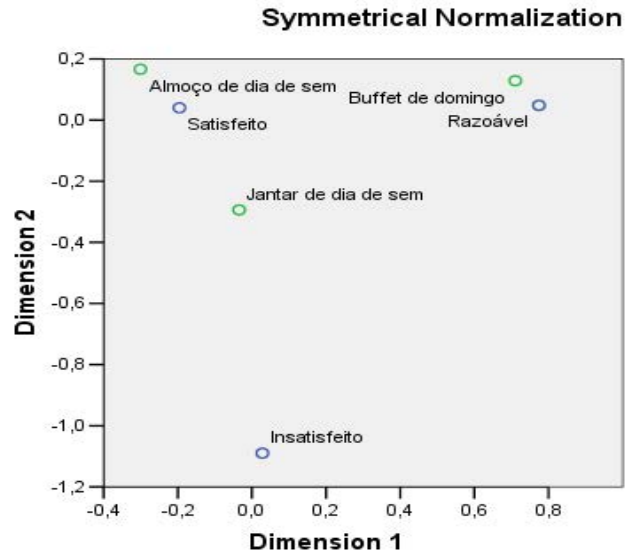

ALIMENTACCÃO [16 Apresentação e Rratos] Refeição

Fonte: elaboração própria.

A variável "refeição" também teve associação significativa $(p=0,002)$ com a variável "apresentação pessoal dos funcionários (uniforme, higiene pessoal, postura)". A Tabela 8 apresenta o percentual de clientes segundo o tipo de refeição e a satisfação com a apresentação pessoal dos funcionários do estabelecimento. O gráfico da AC é apresentado na Figura 8. Conclui-se que aqueles que jantam durante a semana têm maior tendência de estarem satisfeitos com a apresentação pessoal dos funcionários, enquanto que os clientes que frequentam o buffet de domingo têm maior tendência de achar que os funcionários estão razoavelmente apresentados.

Tabela 8: Tipo de refeição $X$ satisfação com apresentação pessoal dos funcionários.

\begin{tabular}{lllll}
\hline & \multicolumn{4}{l}{ Apresentação pessoal dos funcionários } \\
\hline Refeição & Insatisfeito & Razoável & Satisfeito & TOTAL \\
\hline Almoço de dia de semana (À la carte) & $3,5 \%$ & $18,0 \%$ & $78,5 \%$ & $100,0 \%$ \\
Jantar de dia de semana (À la carte) & $3,3 \%$ & $11,7 \%$ & $85,0 \% *^{*}$ & $100,0 \%$ \\
Buffet de domingo & $0,8 \%$ & $29,0 \% *^{*}$ & $70,2 \%$ & $100,0 \%$ \\
TOTAL & $2,9 \%$ & $18,0 \%$ & $79,1 \%$ & $100,0 \%$ \\
\hline
\end{tabular}

Fonte: elaboração própria. 
Figura 8 - 0 gráfico da AC entre Tipo de refeição e satisfação com apresentação pessoal dos funcionários

Row and Column Points

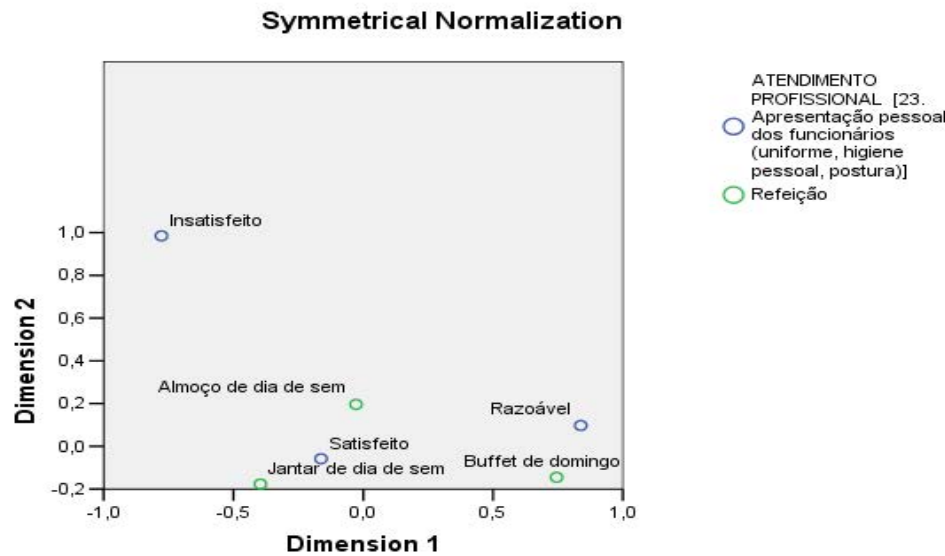

Fonte: elaboração própria.

A variável "refeição" também teve associação significativa $(p=0,025)$ com a variável "Domínio e conhecimento sobre os produtos apresentados no cardápio". A Tabela 9 apresenta o percentual de clientes segundo o tipo de refeição e a satisfação com o domínio e conhecimento sobre os produtos apresentados no cardápio do estabelecimento. O gráfico da AC é apresentado na Figura 9. Conclui-se que aqueles que jantam durante a semana têm maior tendência de estarem satisfeitos com o domínio e conhecimento sobre os produtos apresentados no cardápio.

Tabela 9: Tipo de refeição X satisfação com apresentação e identificação dos pratos.

\begin{tabular}{lllll}
\hline & \multicolumn{4}{l}{$\begin{array}{l}\text { Domínio e conhecimento sobre os } \\
\text { produtos apresentados no cardápio }\end{array}$} \\
\hline Refeição & Insatisfeito & Razoável & Satisfeito & TOTAL \\
\hline Almoço de dia de semana (À la carte) & $4,1 \%$ & $14,7 \%$ & $81,2 \%$ & $100,0 \%$ \\
Jantar de dia de semana (À la carte) & $2,4 \%$ & $7,1 \%$ & $90,5 \% *$ & $100,0 \%$ \\
Buffet de domingo & $0,8 \%$ & $14,8 \%$ & $84,4 \%$ & $100,0 \%$ \\
TOTAL & $2,8 \%$ & $12,0 \%$ & $85,1 \%$ & $100,0 \%$ \\
\hline Fonte: elaboração própria. & & & &
\end{tabular}


ANÁLISE DA ASSOCIAÇÃO ENTRE O PERFIL DE CLIENTE DE UM RESTAURANTE E SEU NÍVEL DE SATISFAÇÃO

Figura 9 - 0 gráfico da AC entre Tipo de refeição e satisfação com Domínio e conhecimento sobre os produtos apresentados no cardápio

Row and Column Points

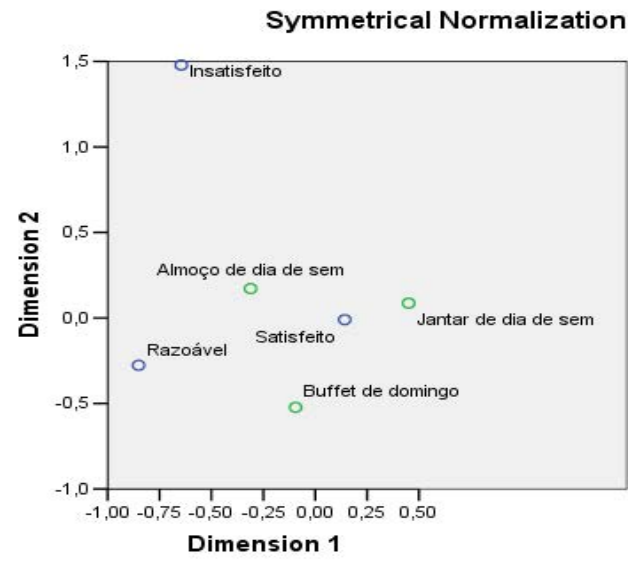

ATENDIMENTO

PROFISSIONAL [24.

Dominio e conhecimento

apresentados no

cardápio]

Refeição

Fonte: elaboração própria.

A variável "refeição" também teve associação significativa $(p<0,001)$ com a variável "agilidade dos atendentes". A Tabela 10 apresenta o percentual de clientes segundo o tipo de refeição e a satisfação com a agilidade dos atendentes. $\mathrm{O}$ gráfico da AC está na Figura 10.

Tabela 10: Tipo de refeição $X$ satisfação com a agilidade dos atendentes.

\begin{tabular}{lllll}
\hline \multicolumn{4}{l}{ Agilidade dos atendentes } \\
\hline & Insatisfeito & Razoável & Satisfeito & TOTAL \\
\hline Refeição & $6,5 \%^{*}$ & $16,8 \%$ & $76,7 \%$ & $100,0 \%$ \\
\hline Almoço de dia de semana (À la carte) & $3,3 \%$ & $11,6 \%$ & $85,1 \% *^{*}$ & $100,0 \%$ \\
Jantar de dia de semana (À la carte) & $1,6 \%$ & $30,1 \% \%^{*}$ & $68,3 \%$ & $100,0 \%$ \\
Buffet de domingo & $4,4 \%$ & $17,7 \%$ & $78,0 \%$ & $100,0 \%$ \\
TOTAL & & & &
\end{tabular}

Fonte: elaboração própria. 
Figura 10 - 0 gráfico da AC entre Tipo de refeição e satisfação com a agilidade dos atendentes

Row and Column Points

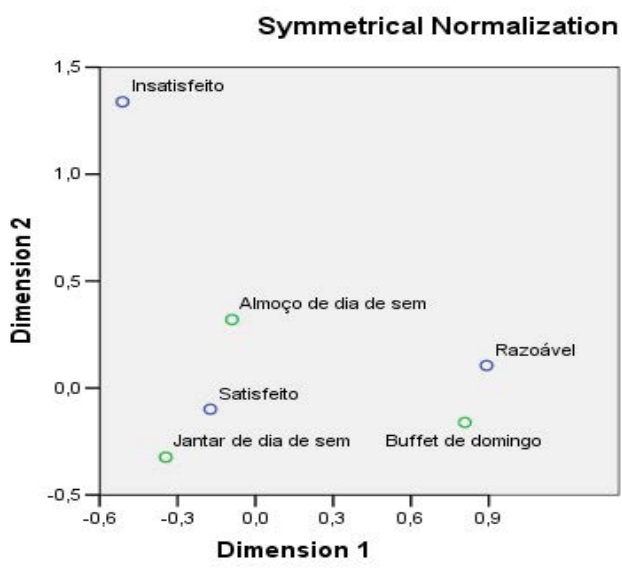

ATENDIMENTO PROFISSIONAL [25. Agilidade dos
atendentes] Refeição

Fonte: elaboração própria.

Conclui-se que os clientes que almoçam durante a semana têm maior tendência de estarem insatisfeitos com a agilidade dos atendentes, e aqueles que jantam durante a semana têm maior tendência de estarem satisfeitos com a agilidade dos atendentes, enquanto que aqueles que frequentam o buffet de domingo têm maior tendência achar que os atendentes são razoavelmente ágeis.

A variável "refeição" também teve associação significativa $(p<0,001)$ com a variável "iniciativa dos atendentes". A Tabela 11 apresenta o percentual de clientes segundo o tipo de refeição e a satisfação com a iniciativa dos atendentes do estabelecimento. O gráfico da AC é apresentado na Figura 11. Conclui-se que os clientes que almoçam durante a semana têm maior tendência de estarem insatisfeitos com a iniciativa dos atendentes, aqueles que jantam durante a semana têm maior tendência de estarem satisfeitos com a iniciativa dos atendentes, enquanto que aqueles que frequentam o buffet de domingo têm maior tendência achar que iniciativa dos atendentes é razoável.

Tabela 11: Tipo de refeição $X$ satisfação com a iniciativa dos atendentes.

\begin{tabular}{lllll}
\hline \multicolumn{4}{l}{ Iniciativa dos atendentes } \\
\hline Refeição & Insatisfeito & Razoável & Satisfeito & TOTAL \\
\hline Almoço de dia de semana (À la carte) & $7,2 \%{ }^{*}$ & $19,8 \%$ & $73,0 \%$ & $100,0 \%$ \\
Jantar de dia de semana (À la carte) & $4,2 \%$ & $14,0 \%$ & $81,9 \%{ }^{*}$ & $100,0 \%$ \\
Buffet de domingo & $1,6 \%$ & $31,5 \%{ }^{*}$ & $66,9 \%$ & $100,0 \%$ \\
TOTAL & $5,0 \%$ & $20,1 \%$ & $74,9 \%$ & $100,0 \%$ \\
\hline Fonte: elaboração própria. & & & &
\end{tabular}

Fonte: elaboração própria. 
ANÁLISE DA ASSOCIAÇÃO ENTRE O PERFIL DE CLIENTE DE UM RESTAURANTE E SEU NÍVEL DE SATISFAÇÃO

Figura 11 - 0 gráfico da AC entre Tipo de refeição e satisfação com a iniciativa dos atendentes

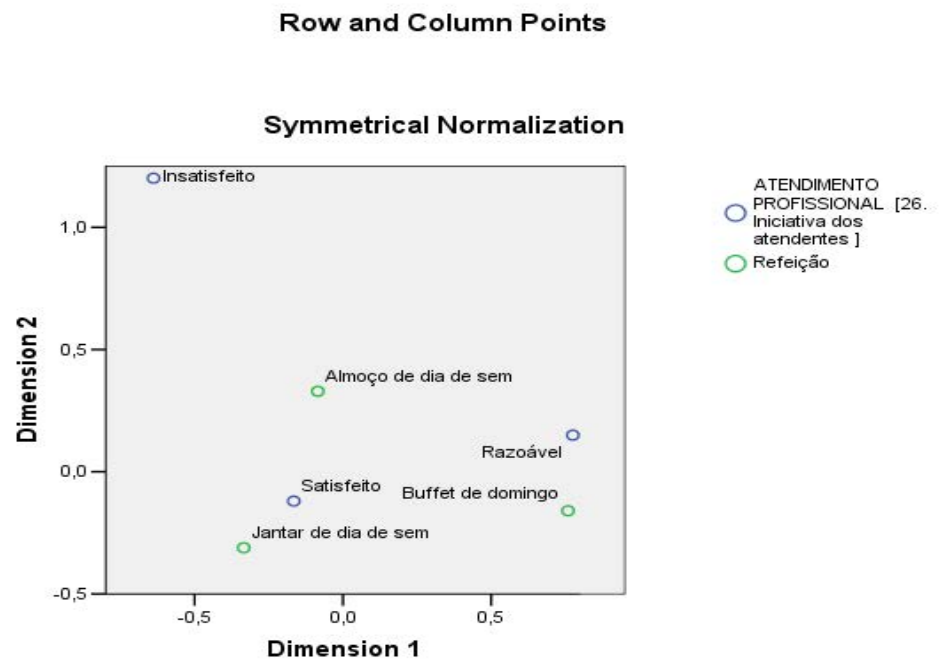

Fonte: elaboração própria.

A variável "refeição" também teve associação significativa $(p=0,022)$ com a variável "preocupação em atender bem o cliente". A Tabela 12 apresenta o percentual de clientes segundo o tipo de refeição e a satisfação com a preocupação em atender bem o cliente. O gráfico da AC é apresentado na Figura 12. Conclui-se que os clientes que almoçam durante a semana têm maior tendência de estarem insatisfeitos com a preocupação em atender bem o cliente, aqueles que jantam durante a semana têm maior tendência de estarem satisfeitos com a preocupação em atender bem o cliente, enquanto que aqueles que frequentam o buffet de domingo têm maior tendência achar que a preocupação em atender bem o cliente os atendentes é razoável.

Tabela 12: Tipo de refeição $X$ satisfação com a preocupação em atender bem o cliente.

\begin{tabular}{|c|c|c|c|c|}
\hline & \multicolumn{4}{|c|}{ Preocupação em atender bem o cliente } \\
\hline Refeição & Insatisfeito & Razoável & Satisfeito & TOTAL \\
\hline Almoço de dia de semana (À la carte) & $5,4 \%$ * & $16,7 \%$ & $77,9 \%$ & $100,0 \%$ \\
\hline Jantar de dia de semana (À la carte) & $2,8 \%$ & $11,2 \%$ & $86,0 \%$ * & $100,0 \%$ \\
\hline Buffet de domingo & $1,6 \%$ & $22,1 \%$ * & $76,2 \%$ & $100,0 \%$ \\
\hline TOTAL & $3,8 \%$ & $15,8 \%$ & $80,4 \%$ & $100,0 \%$ \\
\hline
\end{tabular}

Fonte: elaboração própria. 
Figura 12 - 0 gráfico da AC entre Tipo de refeição e satisfação com a preocupação em atender bem o cliente

Row and Column Points
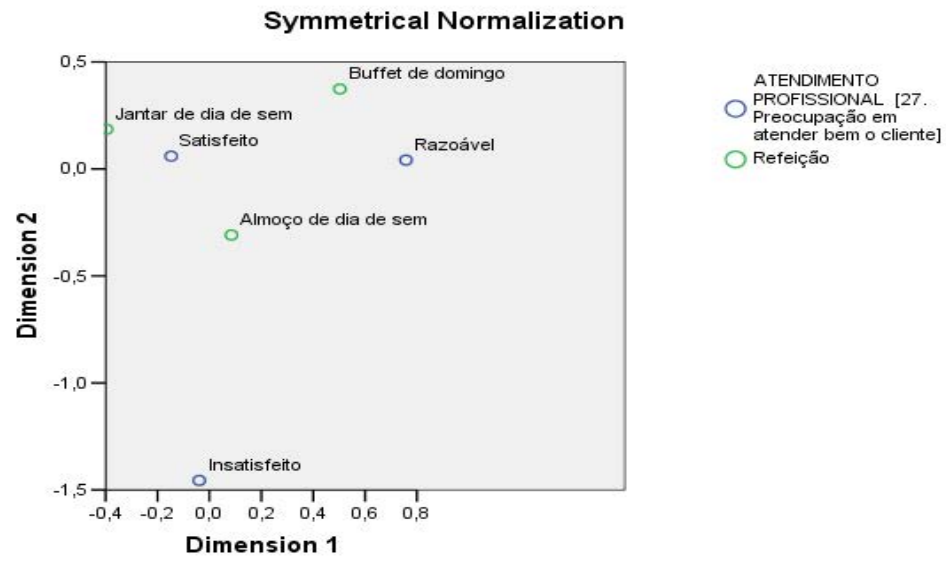

Refeição

Fonte: elaboração própria.

A variável "refeição" também teve associação significativa $(p<0,001)$ com a variável "disponibilidade dos garçons no atendimento". A Tabela 13 apresenta o percentual de clientes segundo o tipo de refeição e a satisfação com a disponibilidade dos garçons no atendimento. O gráfico da AC é apresentado na Figura 13. Conclui-se que os clientes que almoçam durante a semana têm maior tendência de estarem insatisfeitos com a disponibilidade dos garçons no atendimento, aqueles que jantam durante a semana têm maior tendência de estarem satisfeitos com a disponibilidade dos garçons no atendimento, enquanto que aqueles que frequentam o buffet de domingo têm maior tendência achar que disponibilidade dos garçons no atendimento é razoável.

Tabela 13: Tipo de refeição X satisfação com a disponibilidade dos garçons no atendimento.

\begin{tabular}{lllll}
\hline \multicolumn{4}{l}{$\begin{array}{l}\text { Disponibilidade dos garçons no } \\
\text { atendimento }\end{array}$} & \\
\hline Refeição & Insatisfeito & Razoável & Satisfeito & TOTAL \\
\hline Almoço de dia de semana (À la carte) & $10,2 \%{ }^{*}$ & $17,5 \%$ & $72,4 \%$ & $100,0 \%$ \\
Jantar de dia de semana (À la carte) & $2,8 \%$ & $13,0 \%$ & $84,2 \%{ }^{*}$ & $100,0 \%$ \\
Buffet de domingo & $8,9 \%$ & $30,9 \%^{*}$ & $60,2 \%$ & $100,0 \%$ \\
TOTAL & $7,3 \%$ & $18,6 \%$ & $74,1 \%$ & $100,0 \%$ \\
\hline
\end{tabular}

Fonte: elaboração própria. 
ANÁLISE DA ASSOCIAÇÃO ENTRE O PERFIL DE CLIENTE DE UM RESTAURANTE E SEU NÍVEL DE SATISFAÇÃO

Figura 13 - 0 gráfico da AC entre Tipo de refeição e satisfação com a disponibilidade dos garçons no atendimento.

Row and Column Points

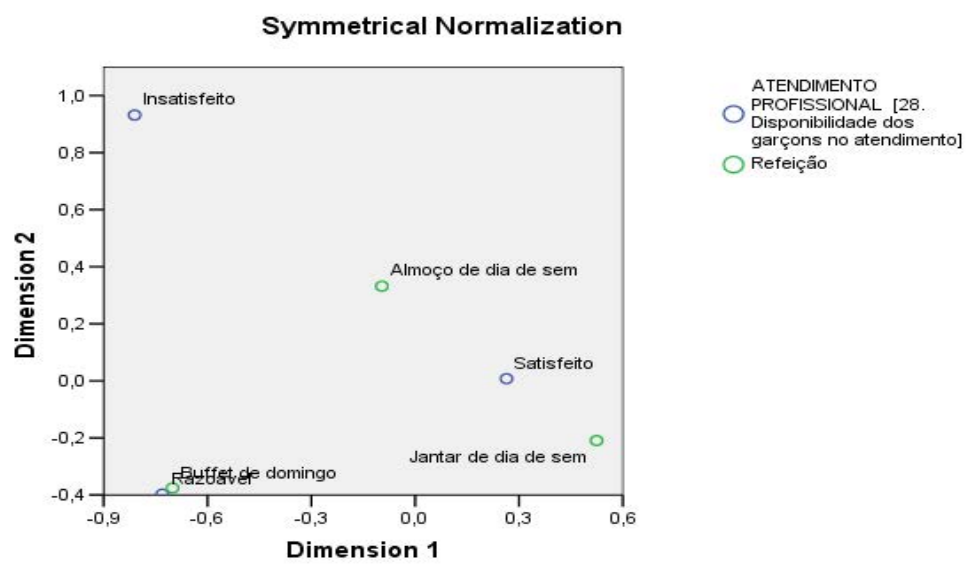

Fonte: elaboração própria.

A Tabela 14 apresenta um resumo das associações significativas encontradas entre o perfil de cliente, segundo seus hábitos de refeição e o nível de satisfação os itens avaliados.

Tabela 14: Associações significativas encontradas

\begin{tabular}{|c|c|c|c|c|}
\hline Item Avaliado & p-valor & Insatisfeito & Razoável & Satisfeito \\
\hline Banheiro & 0,038 & $\begin{array}{l}\text { Almoço de dia de } \\
\text { semana }\end{array}$ & Buffet de domingo & $\begin{array}{l}\text { Jantar de dia de } \\
\text { semana }\end{array}$ \\
\hline Limpeza do estabelecimento & 0,003 & Buffet de domingo & - & $\begin{array}{l}\text { Jantar de dia de } \\
\text { semana }\end{array}$ \\
\hline Cheiro do ambiente interno & 0,004 & Buffet de domingo & $\begin{array}{l}\text { Jantar de dia de } \\
\text { semana }\end{array}$ & - \\
\hline Sinalização do estabelecimento & 0,019 & - & $\begin{array}{l}\text { Jantar de dia de } \\
\text { semana }\end{array}$ & $\begin{array}{l}\text { Almoço de dia de } \\
\text { semana }\end{array}$ \\
\hline Estacionamento & 0,001 & Buffet de domingo & - & $\begin{array}{l}\text { Almoço de dia de } \\
\text { semana }\end{array}$ \\
\hline Organização do buffet & $<0,001$ & - & $\begin{array}{l}\text { Almoço de dia de } \\
\text { semana }\end{array}$ & Buffet de domingo \\
\hline Apresentação e identificação dos pratos & 0,008 & - & Buffet de domingo & $\begin{array}{l}\text { Almoço de dia de } \\
\text { semana }\end{array}$ \\
\hline Apresentação pessoal dos funcionários & 0,002 & - & Buffet de domingo & $\begin{array}{l}\text { Jantar de dia de } \\
\text { semana }\end{array}$ \\
\hline $\begin{array}{l}\text { Domínio e conhecimento sobre os produtos } \\
\text { apresentados no cardápio }\end{array}$ & 0,025 & - & - & $\begin{array}{l}\text { Jantar de dia de } \\
\text { semana }\end{array}$ \\
\hline Agilidade dos atendentes & $<0,001$ & $\begin{array}{l}\text { Almoço de dia de } \\
\text { semana }\end{array}$ & Buffet de domingo & $\begin{array}{l}\text { Jantar de dia de } \\
\text { semana }\end{array}$ \\
\hline Iniciativa dos atendentes & $<0,001$ & $\begin{array}{l}\text { Almoço de dia de } \\
\text { semana }\end{array}$ & Buffet de domingo & $\begin{array}{l}\text { Jantar de dia de } \\
\text { semana }\end{array}$ \\
\hline Preocupação em atender bem o cliente & 0,022 & $\begin{array}{l}\text { Almoço de dia de } \\
\text { semana }\end{array}$ & Buffet de domingo & $\begin{array}{l}\text { Jantar de dia de } \\
\text { semana }\end{array}$ \\
\hline Disponibilidade dos garçons no atendimento & $<0,001$ & $\begin{array}{l}\text { Almoço de dia de } \\
\text { semana }\end{array}$ & Buffet de domingo & $\begin{array}{l}\text { Jantar de dia de } \\
\text { semana }\end{array}$ \\
\hline
\end{tabular}

Fonte: elaboração própria. 
Observa-se que os clientes que almoçam durante o dia de semana possuem insatisfação associada com o banheiro, a agilidade dos atendentes, a iniciativa dos atendentes, a preocupação em atender bem o cliente e a disponibilidade dos garçons no atendimento. Os mesmos clientes possuem satisfação associada com a sinalização do estabelecimento, o estacionamento e a apresentação e identificação dos pratos. Esses clientes também tiveram satisfação razoável associada com a organização do buffet.

Clientes que jantam durante a semana não possuem insatisfação associada a nenhum item. Ao contrário, eles possuem satisfação associada quanto ao banheiro, a limpeza do estabelecimento, a apresentação pessoal dos funcionários, o domínio e conhecimento sobre os produtos apresentados no cardápio, a agilidade dos atendentes, a iniciativa dos atendentes, a preocupação em atender bem o cliente e a disponibilidade dos garçons no atendimento. Esses clientes também tiveram satisfação razoável associada com o cheiro do ambiente interno e a sinalização do estabelecimento.

Clientes que costumam frequentar o restaurante no domingo possuem insatisfação associada com a limpeza do estabelecimento, o cheiro do ambiente interno e o estacionamento. Por outro lado, os mesmos possuem satisfação associada com a organização do buffet. Mas eles tiveram satisfação razoável associada com o banheiro, a apresentação e identificação dos pratos, a apresentação pessoal dos funcionários, a agilidade dos atendentes, a iniciativa dos atendentes, a preocupação em atender bem o cliente e a disponibilidade dos garçons no atendimento.

\section{Conclusões}

O objetivo desse trabalho foi analisar a associação entre o tipo de cliente de um restaurante em Santa Maria - RS, segundo seus hábitos de refeição seu nível de satisfação com o restaurante, por meio de análise estatística do teste qui-quadrado e a análise de correspondência.

A variável "refeição" verificava qual o tipo de refeição que o cliente estava fazendo ou fez no estabelecimento, se era almoço de dia de semana, jantar de dia de semana ou buffet de domingo. Foram encontradas associações significativas com 13 variáveis avaliadas na pesquisa.

As análises mostraram que o banheiro está em melhores condições à noite, durante a janta, do que no almoço, considerando as refeições feitas durante a semana. Da mesma forma, variáveis relacionadas com o atendimento (agilidade dos atendentes, iniciativa dos atendentes, preocupação em atender bem o cliente e a disponibilidade dos garçons no atendimento) foram melhores avaliadas à noite, durante a janta, do que no almoço. Ainda na janta, mais duas variáveis relacionadas com o atendimento tiveram associação com boa satisfação dos clientes: apresentação pessoal dos funcionários e domínio e conhecimento sobre os produtos apresentados no cardápio. 
Nos domingos, variáveis relacionadas com a estrutura do estabelecimento (limpeza do estabelecimento, cheiro do ambiente interno e estacionamento) foram associadas com a insatisfação dos clientes, apesar da organização do buffet ter tido associação com boa satisfação. Variáveis relacionadas com a organização (sinalização do estabelecimento, estacionamento e apresentação e identificação dos pratos) apresentaram associação com a satisfação de clientes que almoçam durante a semana. Os resultados mostraram associações que poderão gerar subsídios para a tomada de decisões e melhorias no restaurante.

\section{Referências}

BARLOW, J.; MOLLER, C. Reclamação de Cliente? Não tem melhor presente: usando o feedback do cliente como uma ferramenta estratégica. São Paulo: Futura, 1996.

BORTOLOTTI, S. L. V. et al . Consumer satisfaction and item response theory: creating a measurement scale. Gest. Prod., São Carlos, v. 19, n. 2, 2012. Disponível em <http://www.scielo.br/scielo.php?script=sci_arttext\&pid=S0104-530X2012000200 005\&lng=en\&nrm=iso>. Acesso em 30 mar 2017.

DUBE, L. et al. Measuring customer satisfaction for strategic management. Cornell Hotel and Restaurant Administration Quarterly, New York: v. 35, n. ${ }^{\circ}$ 1, p.39-48, 1994.

KOTLER, P. Administração de Marketing: Analise, Planejamento, Implementação e Controle. 5. ed. São Paulo: Atlas, 1998.

OLIVEIRA, J. R.; MOREIRA JUNIOR, F. J.; ANSUJ, A. P.; WEISE, A. D. Identificação dos aspectos importantes para os clientes de restaurantes. Revista Espacios, Vol. 36, Ano 2015. Disponível em < http://www.revistaespacios.com/a15v36n08/15360814.html >. Acesso em 30 mar 2017.

OLIVER, R. L. Cognitive, affective, and attribute bases of the satisfaction response. Journal of Consumer Research, Chicago: v. 20, p. 418-430, 1993.

PASSADOR, J. L.; FILHO, D. O. L.; SPANHOL, P. S.; RODRIGUES, F. S.; SABES, J. J. S. A percepção do consumidor de alimentos "fora de casa": um estudo multicaso na cidade de Campo Grande/MS. In: SIMPEP, XIII, Anais..., Bauru, SP, Brasil, 6 a 8 de Novembro de 2006.

PINHEIRO, F. A.; LEITE, A. A. M.; OLIVEIRA, M. S. A. Avaliação da Qualidade Percebida em um restaurante temático-típico. Revista Gerenciais, v.7, n.1, p.53-59, São Paulo, 2008.

ROSSI C. A. V, SLONGO, L. A. Pesquisa de Satisfação de clientes: o Estado-da-Arte e Preposição de um Método Brasileiro. Revista de Administração Contemporânea, 1998.

TONTINI, G.; SANT'ANA, A. J. Identificação de atributos críticos de satisfação em um serviço através da análise competitiva do gap de melhoria. Gestão e Produção, São Carlos, v. 14, n. 1, p. 43-54, jan.-abr. 2007. 